Why Organizational and Community 1

WHY ORGANIZATIONAL AND COMMUNITY DIVERSITY MATTER:

REPRESENTATIVENESS AND THE EMERGENCE OF INCIVILITY AND

ORGANIZATIONAL PERFORMANCE 


\title{
WHY ORGANIZATIONAL AND COMMUNITY DIVERSITY MATTER: REPRESENTATIVENESS AND THE EMERGENCE OF INCIVILITY AND ORGANIZATIONAL PERFORMANCE
}

\begin{abstract}
Integrating sociological and psychological perspectives, this research considers the value of organizational ethnic diversity as a function of community diversity. Employee and patient surveys, census data, and performance indices relevant to 142 hospitals in the United Kingdom suggest that intraorganizational ethnic diversity is associated with reduced civility toward patients. However, the degree to which organizational demography was representative of the community demography was positively related to civility experienced by patients and ultimately enhanced organizational performance. These findings underscore the understudied effects of community context, and imply that intergroup biases manifested in incivility toward outgroup members hinder organizational performance.
\end{abstract}




\section{WHY ORGANIZATIONAL AND COMMUNITIY DIVERSITY MATTER: REPRESENTATIVENESS AND THE EMERGENCE OF INCIVILITY AND ORGANIZATIONAL PERFORMANCE}

Social, political, and technological advancements have given rise to a workforce comprised of people from a wide range of racial and ethnic backgrounds across the globe (United Nations Statistics Division, 2009). Management research on the implications of this increasing ethnic diversity has yielded mixed findings; some research within teams and dyads suggests diversity can generate innovation and breadth of information (e.g., Simmons, Pelled, \& Smith, 1999), while other studies suggest diversity can have negative effects by increasing conflict and reducing cohesion (e.g., Jehn, Northcraft \& Neale, 1999). The little evidence that exists at the level of the organization suggests that diversity can have positive effects on financial outcomes under some conditions (Herring, 2009; Richard, 2000; Richard, Barnett, Dwyer, \& Chadwick, 2004). Researchers have therefore moved past the question of whether diversity affects outcomes and have instead begun to address the question of when and how diversity can facilitate positive outcomes (Joshi \& Roh, 2009).

An answer to these questions may be gleaned from one of the potential value propositions espoused by researchers and practitioners of diversity management: diverse employees may be particularly effective in serving similarly diverse populations (Richard, 2000) by bringing unique cultural sensitivity that appeals to a diverse customer base (Cox \& Blake, 1991). This reasoning can be grounded in social identity and social categorization theories, which suggest that people unconsciously favor members of their own social groups (Tajfel \& Turner, 1979). On its face, this rationale implies that organizational diversity will yield positive effects when it matches the demography of customers or clients the organization serves. 
Here we suggest that the primary reason why people from one ethnic background may be less effective in serving people from other ethnic backgrounds is that the positive regard automatically afforded to ingroup members is replaced by a subtle disregard when intraorganizational diversity does not align with community diversity. Whereas individuals serving others from their own group manifest covert preferences through positive interpersonal treatment, subtle disfavor (i.e., incivility; Andersson \& Pearson, 1999; Cortina, 2008) may emerge when organizational diversity does not represent the demography of the community it serves. Although interpersonal mistreatment is often described as part of the rationale for the complex effects of diversity, it has seldom been measured in management research.

There are three primary goals of this study. First, we examine effects of intraorganizational ethnic demography on incivility in service interactions. This will extend findings from a very small number of studies that empirically test the organizational-level effects of diversity (e.g., Richard et al., 2004) by focusing on incivility as a potential consequence of challenges that arise in intergroup interactions in diverse organizations. Second, this research will provide novel empirical evidence regarding organizational consequences of the degree to which organizational demography represents the demography of the stakeholders that are directly served above and beyond intraorganizational diversity. Third, extending previous theoretical rationale, we reason that incivility toward service recipients can manifest when demographic characteristics are not aligned, and that this incivility will impede organizational success. Thus, the current study will not only clarify the mechanisms through which diversity and representativeness affect performance, but will also provide the first empirical test of organizational outcomes of incivility. We begin by reviewing and synthesizing theories of diversity from psychology and sociology before describing the current hypotheses. 


\section{THEORETICAL FOUNDATION}

Understanding of the dynamics that emerge when ethnically diverse individuals interact can be derived from social identity theory (Tajfel \& Turner, 1979), which purports that the social groups to which individuals belong create distinctions between members of one's own social group and members of other social groups. Social identity groups can emerge as a result of minimal distinctions (e.g., random assignment; Tajfel, Bilig, Bundy, \& Flament, 1971), as well as through visible attributes that convey social standing (e.g., gender, ethnicity; Ellemers, Doosje, \& Spears, 2004). People, who are generally motivated to see themselves in a positive manner (Leary \& Downs, 1995), tend to favor members of their own social identity groups compared to members of other groups. Because the social identity group is viewed as a component of the self, favoring one's ingroup over an outgroup can lead to positive self-views. Unfortunately, these social categories can also lead to destructive intergroup behaviors.

In the context of the workplace, historical patterns of intergoup disadvantage and conflict may become salient. In Blau's (1977) terms, ethnicity can be considered a nominal parameter that differentiates people in terms of subgroups with distinct boundaries. Ethnicity may also carry graduated dimensionality or value given that it is associated with social status; for example, ethnic minorities have lower financial standing than do majority group members. A heightened sensitivity to ethnic differences may be present in contemporary workplaces wherein employees are concerned about relative status and the interpersonal impressions they make (Roberts, 2005). Taken with these factors, the increasing representation of ethnic minorities in organizations has created a situation in which ethnicity is salient in workplace interactions (see DiTomaso, Post, \& Parks-Yancy, 2007). We argue that social identity processes associated with ethnicity can affect organizational-level phenomenon through two complementary processes. First, the nature of 
interactions between members of different ethnic groups will affect organizational phenomena. Second, the representation of members of different ethnic groups within organizationsparticularly relative to the community demography_affects how minority and majority group members view interactions and serves as a cue through which stakeholders understand the norms and expectations of organizations.

Indeed, one of the core components of social identity theory is that the salience of a particular social identity, and the nature of intergroup dynamics more generally, depends on the context in which diverse individuals interact. Thus, we first describe the particular context in which this study is conducted: healthcare organizations. This focus provides an opportunity to consider outcomes of ethnic diversity and intergroup interactions in interdependent and high-risk service relationships. We then theorize that another aspect of context--community demography-is a critical factor for interactions between patients and care providers.

\section{OUTCOMES OF INTRA-ORGANIZATIONAL DIVERSITY}

Service organizations play a critical and growing role in most economies; approximately 70 percent of the workforce in the United States is currently engaged in service-type activities (Mayer, Ehrhart, \& Schneider, 2009). Service organizations vary as a function of several inherent features (Gittell, 2002; Schneider, 2004), including frequency of customer contact with employees, service intangibility (i.e., the degree to which products can be "seen, touched, and held"; Bowen \& Ford, 2002, p. 448), and interdependence (Schneider, 2004). Hospitals can be considered a unique type of service organization in which frequency of customer contact (Lam, Lee, \& Lau, 2004), service intangibility, and interdependence are high (Freeth, 2001).

\section{Diversity in Healthcare Settings}


It is in the context of healthcare organizations that we examine the effects of intraorganizational ethnic diversity, which we conceptualize as the degree of ethnic category variability in organizations (using Blau's index; Harrison \& Klein, 2007). The unique features of healthcare organizations may create conditions under which aspects of readily observable or surface-level differences among employees give rise to negative consequences in the form of incivility toward patients. For example, the dynamic nature of these environments, in which team composition is frequently changed as a result of continually changing professional roles (e.g., medical student, resident, fellow) and schedules (Klein, Ziegert, Knight, \& Xiao, 2006), may affect intergroup interactions. In addition, interactions between patients and providers are similarly constrained in length. When individuals do not have the opportunity to get to know one another in such short-term tasks, observable differences in social identities (like ethnic diversity) are likely to be salient and problematic (Harrison, Price, Gavin, \& Florey, 2002). Another aspect of healthcare organizations that creates intergroup challenges is the high level of risk involved in tasks and decisions that require substantial cognitive and psychological resources (e.g., Boekholdt \& Kanters, 1978). When individuals engage in interactions with people from different social identity groups, they are often anxious, uncomfortable, and concerned about the impression they are making (Hebl \& Dovidio, 2005). These emotional and cognitive processes require individuals in diverse interactions to expend substantial cognitive resources to regulate their behavior (e.g., Richeson \& Shelton, 2003), thereby reducing the resources available for work tasks. In addition, the high level of strain and increased salience of mortality that is created as a result of the suffering of patients may exacerbate intergroup challenges (Chan \& Huak, 2004). Social identity processes of ingroup favoritism and outgroup denigration intensify under such conditions of negative arousal (e.g., Trawalter, Richeson, \& Shelton, 2009) and mortality 
salience (e.g., Schimel et al., 1999). Thus, demographic diversity in healthcare settings may create interactional challenges that ultimately detract from civil treatment of patients.

\section{Incivility as an Outcome of Intraorganizational Diversity}

Incivility is characterized by subtle behaviors that defy social norms, including acting in a discourteous or disrespectful manner. Conversely, civility, or treating others with dignity and respect, bears resemblance to other pro-social workplace behaviors (e.g., citizenship behavior, ingratiation) in that it includes subtle behaviors that are neither required nor formally recognized by the organization (Anderson \& Pearsson, 1999). Previous research suggests that incivility can result from perceptions of distributive and procedural injustice, job dissatisfaction, and exhaustion (Blau \& Andersson, 2005). These experiences create negative affect and stress that impede socially skilled, civil behavior (Johnson \& Indvik, 2001). Similarly, the ingroup favoritism and outgroup derogation that can result from social categorizations offers an explanation for why work interactions between ethnically diverse individuals may engender incivility. Because individuals experience discomfort, anxiety (Hebl \& Dovidio, 2005), and reduced cognitive resources in intergroup interactions (Richeson \& Shelton, 2003) that are more likely in heterogeneous contexts (Blau, 1977), intraorganizational diversity in hospitals creates stress and drains regulatory resources that doctors and nurses might otherwise use in treating their patients with respect and courtesy. For example, a nurse who just experienced conflict with a colleague of a different ethnic group might be less sympathetic toward their patients' complaints. Aggregated across patients to the level of the organization, the social identity processes associated with intraorganizational diversity may result in incivility toward patients: H1: Intraorganizational ethnic diversity is negatively related to civility toward service recipients. 


\section{PERFORMANCE IMPLICATIONS OF CIVILITY}

We further propose that the civility that emerges in service organizations will facilitate organizational performance. In general, customer service quality has been linked with customer satisfaction (Spreng, MacKenzie, \& Olshavsky, 1996), customer retention (Reichheld, \& Sasser, 1990), and financial performance of organizations (Rust, Zahorik, \& Keiningham, 1995). The quality of service encounters affected unit-level customer satisfaction and loyalty in a study of restaurants (Liao \& Chang, 2004) and unit sales in a study of supermarkets (Schneider, Ehrhart, Mayer, Saltz, Niles-Jolly, 2005). We contend that a meaningful element of healthcare interactions that will affect organizational performance is the civility of patient encounters.

Among individual employees in the workplace, subtle mistreatment has been shown to negatively impact job satisfaction, job withdrawal, career salience, psychological distress (Cortina et al., 2001) and self-reported physical health (Lim, Cortina, \& Magley, 2008). When these kinds of disrespectful behaviors are directed toward patients, they too may experience stress, strain, and physical problems that set back recovery. Civil treatment of patients, on the other hand, may engender trust and enable communication that reduces stress and increases the likelihood that patients follow recommended actions. Indeed, respectful communication is a key component of positive doctor-patient relationships (for a review, see Ong, de Haes, Hoos, \& Lammes, 1995). Consistent with this reasoning, the nature of interpersonal experiences in healthcare interactions (communication, respect, and courtesy; Sitzia \& Wood, 1997) have been shown to affect psychological health, symptom resolution (Stewart, 1995), and adherence to recommendations (e.g., Sherbourne et al., 1992). Similarly, civility in provider-patient interactions likely facilitates quicker recoveries, compliance, and ultimately more effective 
allocation of resources. Thus, the aggregate of patient experiences of civility likely supports the performance of healthcare organizations.

Moreover, civility toward patients could affect organizational performance beyond the aggregate effects of individual patients' experiences. Patients who experience civil treatment are likely to express more satisfaction and positive affect than those who experience uncivil treatment (Lim et al., 2008). This positive affect, in turn, could improve the moods of frontline staff through emotional contagion processes (Staw, Sutton, \& Pelled, 1994). Positive moods can give rise to interpersonal helping, actions that protect the organization, personal development, and suggestions to improve organizational functioning (George \& Brief, 1992). Positive affect and experiences can be shared within units (George, 1990) and transmitted throughout the organization as a whole, creating a positive affective organizational climate. Such climates produce cooperative team working and innovation that facilitate organizational outcomes (e.g., Shipton, West, Parkes, Dawson, \& Patterson, 2006). Thus, rationale at the individual and organizational level suggests that civility facilitates organizational performance. Formally,

H2: Civility toward service recipients is positively related to organizational performance.

The previously discussed negative implications of intraorganizational diversity on civility towards patients may ultimately result in these performance decrements; there may be an indirect effect of intraorganizational diversity on organizational performance through civility. Formally,

H3: Intraorganizational diversity is negatively related to organizational performance by reducing civility toward service recipients.

\section{OUTCOMES OF DEMOGRAPHIC REPRESENTATIVENESS}

Considered independently, diversity in healthcare organizations may create challenges that affect interactions with patients. Importantly, however, the same characteristics that create 
internal challenges may create opportunities to serve diverse stakeholders. An understudied contextual factor that likely affects the nature of the relationship between intra-organizational diversity and organizational performance is the demography of the stakeholders served by the organization. Management scholars recognize that extra-organizational factors can influence organizational behavior but rarely assess such aspects of context (see Johns, 2006). A few recent studies highlight the contextual factor of community demography as a predictor of organizational phenomena including diversity climate perceptions (Pugh et al., 2008) and intraorganizational conflict between ethnic minority and majority group members (Brief et al., 2005). We propose that the extent to which the composition of the organization's frontline service employees is representative of the community it serves will be associated with civil treatment of service recipients and ultimately facilitate organizational performance.

\section{Demographic Representativeness in the Healthcare Industry}

The degree to which ethnic diversity of organizations is representative of the relevant community demography_labeled here as demographic representativeness - is presumed to facilitate positive organizational outcomes (Richard, 2000). Diversity efforts are often guided by the expectation that demographic representativeness will facilitate performance, even in the absence of empirical evidence supporting this effect (Leonard, Levine \& Joshi, 2004; Sacco \& Schmitt, 2005). It has also been theorized — but not previously tested-- that demographic representativeness can facilitate understanding of and sensitive treatment toward relevant stakeholders (Morrison, 1992). Indeed, one possible explanation for positive effects of intraorganizational diversity (e.g., Richard et al., 2007) may lie in an unmeasured positive correlation between intra- and extra-organizational demography. 
Demographic representativeness may be particularly important especially in organizations in which employees interact with stakeholders (e.g., service-sector firms; Mittman, 1992; Richard et al., 2007). Consistent with the ingroup favoritism phenomenon, consumers tend to prefer ingroup service providers (Black, Mason, \& Cole, 1996; Sen \& Bhattacharya, 2001). In the healthcare industry, minority patients are more likely to seek and maintain care from minority physicians (LaViest, Nuru-Jeter \& Jones, 2003), and report greater satisfaction with physicians of their same ethnic group than a different ethnic group (LaVeist \& Nuru-Jeter, 1999). When demographic mismatches result in fractured trust or unfriendly communication, healthcare providers may be frustrated, distracted, and dispassionate and patients may lack the information or motivation needed to improve their health. Challenges that arise in mixed-race interactions are one of the explanations given for health disparities across ethnic groups (Perloff et al., 2006).

It is important to note that in each of these studies, the front line service providers who have contact with patients play a critical role in determining organizational outcomes including, health outcomes, patient satisfaction, mortality and productivity (Oliver, 1997). When we considered intraorganizational diversity in isolation, we were interested in the implications of diversity throughout the organization. However, in considering the alignment between community and organizational demography, it is the ethnicity of frontline service providers that may be meaningful. Next, we propose that uncivil behaviors directed toward individuals from other social groups represent the yet-unmeasured experiential mechanisms that account for the effect of demographic representativeness on organizational performance.

\section{Demographic Representativeness and Selective Incivility}

Given that incivility may be selectively enacted toward members of social identity outgroups (Cortina, 2008), we reason that demographic representativeness will give rise to 
civility through both individual and organizational processes. Bottom-up processes influence civility in part because the alignment of employee and community may affect patients' and providers' perceptions. Research and theory suggests that people are more likely to notice and pay attention to ethnicity when members of their own group are rare (e.g., distinctiveness; McGuire, 1984; tokenism, Kanter, 1977). This is particularly likely when a patient's ethnic group is represented in a hospital to a lesser or greater degree than is typical in the community-shifts in relative representation are monitored and detected by group members. A complementary phenomenon is likely experienced by care providers: as the proportion of patients from particular ethnic groups increases relative to the composition of providers, providers may feel challenged or threatened (i.e., realistic group conflict theory; Bobo, 1983). The increased salience of ethnicity as a function of representativeness likely shapes patient-provider interactions.

Moreover, the assignment of providers to patients may not be perfectly random; instead, patients and providers may choose or be assigned to service encounters with those of similar ethnic backgrounds. Indeed, ethnic minority patients and doctors are more likely to have ethnic minority doctors and patients than are majority group members (Gray \& Stoddard, 1997). When healthcare providers and patients are from different ethnic groups, greater effort may be required to understand patients' requests and needs (Skaggs \& Huffman, 2003). Patient involvement in the care they receive may further add to the unpredictability service providers experience when attempting to gauge interactions (Bowen \& Schneider, 1988). These uncertainties may tax cognitive and regulatory resources leaving service professionals more vulnerable to applying stereotypes of patients (Wigboldus, Sherman, Franzese, \& van Knippenberg, 2004). When patients observe doctors and nurses from their own ethnic group in the hallways of hospitals, they may feel more at ease interpersonally, comfortable asking questions, trusting of 
recommendations, and may expect to be treated more fairly than in hospitals that are less demographically representative. These aspects of diverse patients' experiences can be associated with health-related outcomes (Perloff et al., 2006). It follows that, because demographic representativeness of hospitals increases the availability of same-ethnicity providers for patients, demographic representativeness will give rise to civility.

Demographic representativeness may also enhance civility through top down processes such as the creation of organizational norms of civility toward diverse people. Representation of ethnic minorities serves as a visible and observable cue through which stakeholders understand the meaning of ethnicity in a particular context (McKay \& Avery, 2006; Roberson \& Stevens, 2006). Demographically representative organizations may signal an integration-and-learning perspective of diversity (Ely \& Thomas, 2001), viewing diversity as a resource through which to gain valuable organizational benefits. Moreover, representation can influence the degree to which organizations are perceived to be supportive of diversity (King, Hebl, George, \& Matusik, 2010; Mor Barak et al., 1998). In organizations that are low in demographic representativeness, stakeholders such as employees and customers infer that diversity is not an organizational priority and organizational norms do not include support for ethnically diverse individuals. A lack of demographic representativeness may signal reluctance on the part of the organization to embrace inclusive norms (Pugh et al., 2008), whereas alignment between community and organizational demography would suggest that organizations have instituted fair and equitable attraction, hiring, and retention practices. Because behavior of service providers in demographically representative organizations is influenced in part by the norms created and promoted through a climate that supports equality (Cox \& Blake, 1991), representativeness likely engenders civil treatment of service recipients. The top-down and bottom-up processes that result 
from demographic representativeness are complementary and convergent; demographic representativeness promotes civility and ultimately organizational performance through both individual and organizational constraints. It follows that,

H4: Demographic representativeness is positively related to civility toward service recipients (H4a), even after controlling for intraorganizational and community diversity (H4b).

H5: Demographic representativeness is positively related to organizational performance by enhancing civility toward service recipients.

\section{METHOD}

\section{Sample}

This study combines four publicly available, national English data sets. The analysis is conducted at an organizational level on a sample defined as all non-specialist acute 'trusts' in the National Health Service (NHS). An acute trust is a semi-autonomous organization within the NHS that provides hospital care to the local community: this will either be a single hospital, or two or more hospitals within the same geographical area (e.g. city) that operate under the same overall management. The total sample included 142 trusts, henceforth referred to as "hospitals."

The first data source utilized was the NHS National Staff Survey, an annual survey covering all NHS organizations in England, including a sample of up to 850 staff in each organization (Care Quality Commission, 2009a). We use the staff survey data to capture the demographic profile of the employees. The overall response rate in 2007 was $54 \%$ for a total of 68,719 respondents. The second data source was the UK Census, a ten-yearly national survey covering the whole of the UK population. Third, the NHS Acute Inpatient Survey is an annual survey covering all NHS hospitals in England, including a sample of up to 850 patients who 
spent at least one night in hospital during the year (Care Quality Commission, 2009b). Fourth, the Annual Health Check is the official performance rating system of the NHS, conducted annually by the official healthcare regulator (Care Quality Commission, 2009c).

\section{Measures}

Organizational diversity. Organizational diversity was measured using ethnicity data from the NHS National Staff Survey in 2007. Each respondent stated their ethnic background from the following list of options: White (White British, White Irish or White Other), Mixed (White and Black Caribbean, White and Black African, White and Asian, Any other mixed background), Asian/Asian British (Indian, Pakistani, Bangladeshi, Any other Asian Background), Black/Black British (Caribbean, African, Any other Black background), Chinese or Any other ethnic background. However, the most salient categories are the main groupings: White, Mixed, Asian/Asian British, Black/Black British and Other, and these larger groupings are those that are most often reported in official statistics; importantly for this study, it is also the level of data available to us for community characteristics. For that reason we use these five categories to calculate organizational diversity for each hospital using Blau's index, as a measure of variety (Harrison \& Klein, 2007). Blau's index is an indicator of variability in categories that can be interpreted as the probability that any two individuals come from separate categories and is a common measure for assessing variability in ethnic categories.. A perfectly homogenous group would have an index of 0 and a perfectly heterogeneous group with an infinite number of categories in which members were equally represented would have an index of 1. As in England generally, the predominant ethnic group was White, but the proportion of White staff ranged from $43 \%$ to $98 \%$ across organizations $(M=85 \%)$. Blau's index ranged from .05 to .69 suggesting there was a wide range in levels of organizational diversity. 
Community diversity. To measure community diversity, we used data from the most recent UK census (2001) to inform us of the ethnic makeup of each "LSOA" (Lower Super Output Area) - a spatial unit covering an area of population of around 1,500 people on average. Geographic Information Systems (GIS) mapping captures data linked to specific geographic locations. In this case, GIS was used to calculate the distance to each hospital for each LSOA population-weighted centroid. LSOAs, and therefore individual census respondents, were then assigned to the closest hospital geographically. Where an organization included more than one hospital building, each LSOA was mapped to the nearest hospital, and the total of all LSOAs mapped to any hospital within an organization was taken to be the local community for that organization. It is generally the case that, due to the publicly-funded nature of the NHS, individuals will be treated at an organization that is close to where they live. Community diversity was then calculated using Blau's index in the same way as organizational diversity. Again, the predominant ethnic group was White, but the proportion of White members of a community ranged from $42 \%$ to $99 \%$ (mean $91 \%$ ). The value of Blau's index ranged from .01 to .68 suggesting there was also a wide range in levels of community diversity.

Demographic representativeness. To measure how representative the employees of an organization were of the local community in terms of ethnicity, we applied the KolmogorovSmirnov $D_{n}$ statistic (Massey, 1951), which is most often used to test the representativeness of a sample for a given population. It is calculated as

$$
D_{n}=\sup _{x}\left|F_{n}(x)-F(x)\right|
$$

where sup represents the supremum function, $F_{n}(x)$ is the proportion of employees in the first $x$ ethnic groups (ordered by frequency) and $F(x)$ is the proportion of the community in the same first $x$ groups. We used the community characteristics described above 
for the community data; however, for the organizational data we restricted the data used to doctors and nurses, as these are the two groups who have the majority of the contact with hospital inpatients. This measure effectively describes the maximum discrepancy between a profile of one sample (i.e. the organization) and a profile of another sample (i.e. the community), when comparing the cumulative distributions of the two samples, rather than being a direct difference between two variables. It would be at its minimum when the profiles are exactly matched, and at its maximum when there was no correspondence whatsoever. Given this latter situation is unlikely (in that the hospital staff are largely drawn from the local community population), it is worth noting that it would be particularly where the predominant ethnic group in the local community is very under-represented in the staff profile. To ensure that this variable could be interpreted as representativeness we reversed it before including it in analysis.

Civility toward service recipients. The extent of civility shown towards service recipients was measured using the NHS Acute Inpatient Survey. In 2007 this survey had a response rate of $60 \%$, which represented 75,949 total respondents, who had received treatment in the summer of 2007. A number of the questions in the survey asked about the manner in which patients were treated by hospital staff. For each of these questions, a score between 0 and 100 was published for each organization, where 0 represents all patients giving the least favorable response possible and 100 represents all patients giving the most favorable response possible.

Fourteen questions relating specifically to the civil treatment of patients by staff were selected for a factor analysis (see Appendix; an example item is "Overall, did you feel you were treated with respect and dignity while you were at the hospital?"). An exploratory factor analysis revealed that one factor accounted for $64 \%$ of the variance in these 14 items, and all items loaded significantly onto this factor. Cronbach's alpha for the 14 items was 0.95 , suggesting that a 
single score represents civility towards service recipients. The organizational aggregate score was reliable for this measure: $\operatorname{ICC}(2)$ was 0.94 ; additionally, there was a high level of agreement between patients, with $\mathrm{r}_{\mathrm{wg}(\mathrm{j})}$ (James, Demaree \& Wolf, 1993) ranging from 0.83 to 0.97 between organizations, with a mean value of 0.91 . The ICC(1) was 0.031 , indicating that just over $3 \%$ of the variation in incivility can be explained by organization. Together, these statistics suggest that incivility is not characteristic of all patient episodes but that mean scores differ reliably between organizations.

Organizational performance. The regulator of the NHS - the Care Quality Commissionundertakes an annual large scale performance monitoring procedure on all NHS organizations, called the Annual Health Check (AHC). A variety of process and performance measures are taken into account in the AHC, including: patient mortality, achievement of performance targets in specific health areas such as strokes, maternity care, heart disease, infection rates, waiting times, complaints, achievement of financial targets, equality of access to treatment, and quality of partnership working with community organizations. The outcome is two simple ratings for each organization: one item assessing overall quality of services provided, and another item assessing the effective use of resources. These can be thought of as measures of care quality and use of resources respectively. The measures used in this paper are based on the NHS year that ran from April 2007 to March 2008, with the measures being published in October 2008.

Quality of care was rated on a four-point ordinal scale, with scores of "Weak", "Satisfactory", "Good" and "Excellent" available. This outcome is indicative of the extent to which each organization is (a) meeting the government's core standards and (b) making and sustaining improvements in priority areas. In $2007 / 8,4 \%$ of organizations were considered "weak" with regard to quality of care, 17\% "fair", 49\% "good", and 30\% "excellent." Use of 
resources was rated on the same four-point ordinal scale. The use of resources outcome draws from financial audits to assess each organization's financial reporting, management, and standing, and the economy, efficiency, and effectiveness of the resources utilized. In $2007 / 8,8 \%$ of organizations were considered "weak", 32\% "fair", 21\% "good", and 39\% "excellent".

Control variables. In all analyses we controlled for the size of the hospital (measured as the number of employees), location (defined as within or outside London), and socioeconomic status. Size was controlled for because one of the outcome variables, use of resources, could potentially be affected by size (larger hospitals may have comparatively more resources available to them due to economies of scale), and location was included because previous research has shown that some characteristics, notably patient satisfaction, are significantly different in London compared with the rest of the country. Socioeconomic status was measured using the Index of Multiple Deprivation (IMD) score from the English Indices of Deprivation (ODPM, 2004). This spatially-distributed dataset systematically combines a range of local metrics into numerical deprivation scores for individual areas including: income, employment, education and skills, crime, housing and services, and the living environment. Higher levels indicate greater economic disadvantage (see Office of the Deputy Prime Minister, 2004; Department for Communities and Local Government, 2007). Organizational-level scores were calculated using similar methods to community diversity: the IMD score for each LSOA was assigned to the local hospital, with scores weighted by LSOA population during the aggregation process.

\section{RESULTS}

Table 1 shows descriptive statistics and intercorrelations of all study variables. The significant correlations between location (whether an organization was based in London or not) and all other variables justify its inclusion as a control variable. Because of these strong 
correlations, we also considered the possibility that location may act as a moderator of the relationships we tested: however, no such interactions were found.

INSERT TABLES $1 \& 2$ ABOUT HERE

Table 2 shows the results of regression analyses used to test hypotheses 1 to 3 . In the case of hypothesis 1 , these are ordinary least-squares regression analyses, but in the case of hypothesis 2 and 3 they are ordinal logistic regression analyses to allow for the ordinal outcome variables (as performance was measured by four-point ordinal scales, with anchors of "Weak", "Satisfactory", "Good" and "Excellent"). The first column shows that there is a strong relationship between intraorganizational diversity and civility towards service recipients $(B=-$ $\left.11.41, p<.001 ; \beta=-0.76, \Delta \mathrm{R}^{2}=.06\right)$, such that greater diversity is associated with lower levels of civility, supporting Hypothesis 1 . In line with literature suggesting that diversity may have a curvilinear effect with some outcomes (e.g., Richard et al., 2004), we also tested for a curvilinear (quadratic) effect; however, this was not significant $(p=.67)$, and so our original hypothesis of a linear effect was supported.

The second and third columns of table 2 show that there is a significant (and moderately large) relationship between civility and both quality of services $\left(\mathrm{B}=0.27, p<.001, \Delta \mathrm{R}^{2}=.09\right)$ and use of resources $\left(\mathrm{B}=0.25, p=.001, \Delta \mathrm{R}^{2}=.07\right)$ performance measures, such that the more civility reported by patients, the better the organizational performance (supporting Hypothesis 2).

To test Hypothesis 3, which specifies a mediated relationship from intraorganizational diversity to performance via civility towards service recipients, it is necessary to test for an 
indirect effect. Following recent scholarly debate about testing for mediation, we note that it is not necessary to demonstrate a direct effect between the independent and dependent variables before testing the indirect effect, as this may not always be apparent even when indirect effects are present (Shrout \& Bolger, 2002). Instead, we use test of the indirect effect using bootstrapping to test for significance (Preacher \& Hayes, 2004), having demonstrated the independent variable-mediator and mediator-dependent variable links in hypotheses 1 and 2. Because the outcomes were ordinal in nature, we used Mplus (Muthén \& Muthén, 2006) to estimate the indirect effect.

The coefficients for the direct and indirect effects on performance from this Mplus analysis are shown in the final two columns of table 2 . The indirect effects on both outcomes were significant (for quality of services, $B=-1.89, \beta=-0.29, p<.01$; for use of resources, $B=$ $1.96, \beta=-0.29, p=.01)$. Thus, there evidence of an indirect effect of intraorganizational diversity on performance via civility shown towards patients, and hypothesis 3 is supported.

Table 3 shows the results of regression analyses used to test hypotheses $4 \mathrm{a}, 4 \mathrm{~b}$ and 5 . For hypotheses $4 \mathrm{a}$ and $4 \mathrm{~b}$, these are ordinary least-squares regression analyses, but in the case of hypothesis 5 they are again ordinal logistic regression analyses. The first column shows that there is a fairly strong relationship between demographic representativeness and civility towards service recipients $\left(B=12.05, p<.001 ; \beta=0.37, \Delta \mathrm{R}^{2}=.09\right)$, such that greater representativeness is associated with lower levels of civility, supporting Hypothesis 4a. The second column tests the same relationship but including both organizational and community diversity as control variables. It can be seen that there is still a moderately strong and significant relationship between demographic representativeness and civility towards service recipients $(B=13.46, p=$ $.027 ; \beta=0.42, \Delta \mathrm{R}^{2}=.02$ ), such that greater representativeness is associated with lower levels of 
civility, supporting Hypothesis $4 \mathrm{~b}$. Furthermore it can be seen that neither diversity variable is a significant predictor in this model. Nevertheless, due to the large correlations between demographic representativeness and the diversity variables, and therefore concerns about the possible impact of multicollinearity, we conducted relative importance analysis (Johnson, 2000). This showed that the relative weight of representativeness was $33.2 \%$, compared with $24.5 \%$ and $23.0 \%$ for organizational and community diversity respectively, thus confirming that the significant effect was not caused by multicollinearity.

\section{INSERT TABLE 3 ABOUT HERE}

For hypothesis 5, we again used Mplus to estimate the indirect effects. Coefficients from this analysis are shown in the final two columns of Table 3. For the quality of services outcome, there was a significant indirect effect of representativeness $(B=2.33, \beta=0.17, p=.02)$. This suggests that the more representative the employees of a hospital are of the local community, the greater the extent of civility towards patients, and the better the quality of care as a result. There was no significant direct effect between representativeness and quality of services $(B=1.74, \beta=$ $0.13, p=.59$; suggesting that the mediation effect is full (or close to full) mediation. For the use of resources outcome, there was also a significant indirect effect $(B=2.24, \beta=0.15, p=.01)$. This suggests that the more representative the employees of a hospital are of the local community, the greater the extent of civility towards patients, and the more effective the hospital is as a result. There was still, however, a significant direct effect between representativeness and use of resources $(\mathrm{B}=8.76, \beta=0.59, p=.01)$, suggesting that this effect is partial mediation, so 
the combined results suggest that at least one of the main effects of representativeness on performance occurs via patient experiences. Importantly, there was no longer a significant indirect effect of intraorganizational diversity for either outcome $(B=0.46, \beta=0.07, p=.67$ for quality of services; $B=0.46, \beta=0.06, p=.66$ for use of resources). To consider the importance of the construct of representativeness, we also tested interactions between intraorganizational and community diversity and found no evidence of their joint effects. Thus hypothesis 5 is supported.

\section{DISCUSSION}

Three primary contributions emerge from this research. First, adding to a small number of studies empirically testing the effects of organizational-level ethnic diversity (Herring, 2009; Richard, 2000; Richard et al, 2004; 2007), the results suggest that ethnic diversity in hospital staff was negatively associated with civil treatment of patients. However, considering diversity of frontline healthcare providers relative to community diversity points to different interpretations: demographic representativeness was positively associated with civility experienced by patients (even after controlling for intraorganizational and community diversity). Third, the data suggest that enhanced civility toward service recipients facilitates organizational performance. Together, these results have implications for theoretical and practical questions regarding diversity in organizations.

When examining intraorganizational demography without reference to the community context, employee ethnic diversity seemed to get in the way of civility toward service recipients and ultimately organizational performance. These findings should be interpreted in light of previous work suggesting that ethnic diversity can have positive effects on organizational performance (e.g., Herring, 2009; Richard et al., 2004; 2007). The discrepancy in findings could be explained by the nature of the samples; healthcare settings may be uniquely vulnerable to 
dysfunctional social categorization processes because of frequent customer contact (Lam, Lee, \& Lau, 2004), intangible service outcomes, and the interdependent nature of work in healthcare teams (Freeth, 2001). Perhaps more importantly, we focused here on the unique outcome of incivility toward service recipients. Our findings suggest that demographic diversity among employees might create stress or deplete resources that can facilitate civility.

At the level of the team, one of the reasons that the relationship between demographic diversity and team performance is inconsistent across samples is variability in the nature of the context within which the teams function (e.g, industry; Joshi \& Roh, 2009). The data presented here suggest that, at the level of the organization, community demography may play a similar role; considering intraorganizational demography in conjunction with extraorganizational demography yields different interpretations than intraorganizational demography alone. Extending the principles of social identity theory (Tajfel \& Turner, 1979), which suggest that people generally prefer members of their own ethnic group, demographic representativeness facilitated dimensions of hospital performance through its effects on incivility.

The general tendency of management scholars to ignore community factors may be particularly problematic with regard to service organizations wherein business relies upon interactions between the organization and the community. It is notable that, whereas a few previous studies have considered the interaction between organizational and community demography (Brief et al., 2005; Pugh et al., 2008), this study focuses on the ethnic profile of a community relative to the demographic profile of the organization. Thus, this research underscores previous calls to incorporate the community in management theory (e.g., Johns, 2006), and highlights the importance of the novel construct of demographic representativeness. 
These findings are in line with the basic premise underlying the value-in-diversity proposition that individuals may be better positioned to serve those from their same social identity groups. The theory and hypotheses presented in this paper could be interpreted as supporting a matching principle whereby ethnic minority and majority group members are positioned in roles where they serve ethnic minority or majority group members, respectively (see Brief, Butz, \& Deitch, 2005; Carrington \& Troske, 1998). However, we interpret the findings to suggest that a representative organization communicates value and support for the populations they serve. Representative organizations may give employees more experience and practice engaging with people from different perspectives, facilitating their performance with patients. Moreover, by identifying civility as the mechanism accounting for the relationship between demographic representativeness and organizational performance, this paper instead suggests that ethnic diversity itself is not the problem and matching is not the solution. Instead, the challenge is that general tendencies toward ingroup favoritism (Tajfel \& Turner, 1979) can manifest in subtly negative - uncivil—behaviors toward outgroup members (Cortina, 2008).

Organizations, therefore, have an opportunity to improve performance by creating and maintaining norms of civility. Indeed, the current findings are the first to empirically demonstrate that civility is a meaningful predictor of organizational performance. Extending organizational efforts to engender norms for customer service orientation and to improve customer satisfaction (e.g., Schneider, Ehrhart, Mayer, Saltz, Niles-Jolly, 2005; Rogg, Schmidt, Shull, \& Schmitt, 2001), training programs and leadership activities might help employees overcome their (often unconscious) behavioral tendencies to disfavor outgroup members by encouraging civility across all interactions. Given the resistance and backlash that sometimes 
emerge in response to the terms "diversity" and "discrimination," it is possible that focusing on "civility" instead could improve the efficacy of existing diversity management programs.

These findings must be considered, and future research designed, in light of several methodological limitations. First, the generalizability of the findings across cultures and types of organizations may be questioned. Hospitals in the U.K. are part of a nationalized healthcare system that may be subject to different pressures and expectations than other types of organizations in other parts of the world. The dynamic nature of hospital work may also prohibit the opportunity for meaningful intergroup contact, which might otherwise reduce the salience and problematic nature of observable differences in social identity (e.g., Harrison et al., 2002). In addition, the nature of intergroup relations can vary across cultures; for example, the ethnic diversity measured in this study points to the potentially- culturally specific importance of nonBritish immigrants. The boundary conditions for generalization might include service organizations with frequent customer contact, interdependent work, and intangible service outcomes in a Western culture. Nevertheless, we contend that the effects of demographic representativeness on service recipient experiences should generalize to other service environments. A clear direction for future research is to test the hypotheses presented in this paper in other cultures and across organization types.

Second, the measure of the construct of incivility used in this study has not been previously validated. This concern is somewhat mitigated by the fact that the items reflect the conceptual components of respect and courtesy that are typically addressed in measures of civility and are internally consistent (e.g., Cortina et al., 2001). Third, it is possible that there were systematic differences in the likelihood that employees responded to their survey as a function of ethnicity that may yield a biased estimate of organizational diversity. However, the 
profile of ethnicity amongst respondents is very similar to the national profile as indicated by overall NHS workforce statistics. Fourth, the nature of the available data precludes causal inferences; it is possible that alternative models could be posed to explore the patterns of relations between variables. It is particularly important to note that the performance ratings and civility surveys were conducted at essentially the same time. Poor performance could affect employee and customer attitudes, rather than the reverse (Schneider et al., 2005).

Fifth, high correlations between some of the variables - particularly organizational diversity, community diversity and demographic representativeness - give rise to potential concerns about multicollinearity between predictors in some of the analysis. To this end we applied relative importance analysis (Johnson, 2000) for hypothesis $4 \mathrm{~b}$, which showed that the demographic representativeness had far greater importance than the other diversity variables. Sixth, the amount of variance in organizational performance explained by civility is small (1$6 \%$ ). Nevertheless, being able to explain, predict, and influence even small percentages of performance can be critical for organizations. In addition, given the complexity of the task and range of influences on the quality of services, the fact that representativeness can explain even $1 \%$ could be of great importance. Seventh and finally, although a strength of this work is its focus on organizational-level phenomena, it would also be useful to consider individual-level processes that give rise to incivility in service provider-recipient interactions. While the current study was focused on incivility toward service recipients given its anticipated proximal effects on organizational performance, future research should also explore incivility toward co-workers and among community members.

\section{CONCLUSION}


The results of the current study suggest that when organizations do not reflect the demography of the communities in which they are embedded, dysfunctional social categorization processes and manifestations of negative intergroup behaviors can emerge. In light of global trends toward increasingly diverse communities and workplaces, it is imperative that management scholars and practitioners attend to demography both within and outside of organizations. Ultimately, organizations may be most successful when the challenges that arise from diverse interactions are overcome through civility. 
Why Organizational and Community 30

\section{REFERENCES}

Andersson, L. M., \& Pearson, C. M. 1999. The spiraling effect of incivility in the workplace. The Academy of Management Review, 24: 452-471.

Baron, R. M., \& Kenny, D. A. 1986. The moderator-mediator variable distinction in social psychological research: Conceptual, strategic, and statistical considerations. Journal of Personality and Social Psychology, 51: 1173-1182.

Black, G., Mason, K., \& Cole, G. 1996. Consumer preferences and employment discrimination. International Advances in Economic Research, 2: 137-45.

Blau, P. M. 1977. A macrosociological theory of social structure. American Journal of Sociology, 83: 26-54.

Blau, G., \& Andersson, L. 2005. Testing a measure of instigated workplace invicility. Journal of Occupational and Organizational Psychology, 78: 595-614.

Bobo, L. 1983. Whites' opposition to busing: Symbolic racism or realistic group conflict? Journal of Personality and Social Psychology, 45: 1196-1210.

Boekholdt, M. G., \& Kanters, H. W. 1978. Team nursing in a general hospital: Theory, results, and limitations. Journal of Occupational Psychology, 51: 315-325.

Bowen, J., \& Ford, R. C. 2002. Managing service organizations: Does having a "thing" make a difference? Journal of Management, 28: 447-469

Bowen, D.E., \& Schneider, B. 1988. Services marketing and management: Implications for organizational behavior. In B. M. Staw \& L. L. Cummings (Eds.), Research in organizational behavior (Vol.10, pp. 43-80). Greenwich, CT: JAI Press.

Brief, A. P., Butz, R. M., \& Deitch, E. A. 2005. Organizations as reflections of their environments: The case of race composition. In R. Dipboye \& A. Colella (Eds.), The 
Why Organizational and Community 31

psychological and organizational bases of discrimination at work. San Francisco: Jossey- Bass.

Care Quality Commission. 2009a. Surveys of NHS Staff.

http://www.cqc.org.uk/usingcareservices/healthcare/nhsstaffsurveys.cfm. Accessed on 23 December 2009.

Care Quality Commission. 2009b. Inpatient services.

http://www.cqc.org.uk/usingcareservices/healthcare/patientsurveys/hospitalcare/inpatient services.cfm. Accessed on 23 December 2009.

Care Quality Commission. 2009c. Annual Health Check 2007/08.

http://www.cqc.org.uk/guidanceforprofessionals/healthcare/nhsstaff/annualhealthcheck20 07/08.cfm. Accessed on 23 December 2009.

Carrington, W.J., \& Troske, K.R. 1998. Interfirm segregation and the black/white wage gap. Journal of Labor Economics, 16: 231-260.

Cortina, L. M. 2008. Unseen injustice: Incivility as modern discrimination in organizations. Academy of Management Review, 33: 55-75.

Cortina, L.M., Magley, V.J., Williams, J.H., \& Langhout, R.D. 2001. Incivility in the workplace: Incidence and impact. Journal of Occupational Health Psychology, 6: 64-80.

Cox, T. H., \& Blake, S. 1991. Managing cultural diversity: Implications for organizational competitiveness. The Executive.

Department for Communities and Local Government 2007. Investigating the impact of changing the weights that underpin the Index of Multiple Deprivation 2004. Available online: http://www.communities.gov.uk/documents/communities/pdf/323211.pdf

DiTomaso, N., Post, C., \& Parks-Yancy, R. 2007. Workforce diversity and inequality: Power, 
status, and numbers. Annual Review of Sociology, 33: 473-501.

Dovidio, J. F., Kawakami, K., \& Gaerner, S. L. 2002. Implicit and explicit prejudice and interracial interaction. Journal of Personality and Social Psychology, 82: 62-68.

Ellemers, N., Doosje, B., \& Spears, R. 2004. Sources of respect: The effects of being liked by ingroups and outgroups. European Journal of Social Psychology, 34: 155-17.

Ely, R. J., \& D. A. Thomas. 2001. Cultural diversity at work: The effects of diversity perspectives on workgroup processes and outcomes. Administrative Science Quarterly, 46: 229-273.

George, J. M. 1990. Personality, affect, and behavior in groups. Journal of Applied Psychology, 75: 107-116.

George, J. M., \& Brief A. P. 1992. Feeling good- doing good: a conceptual analysis of the mood at work- organizational spontaneity relationship. Psychological Bulletin, 112: 310- 329.

Gittell, J. H. 2002. Relationships between service providers and their impact on customers. Journal of Service Research, 4: 299-311.

Gray, B., \& Stoddard, J. J. 1997. Patient-physician pairing: does ethnic congruity influence selection of a regular physician? Journal of Community Health, 22: 247-259.

Harrison, D. A., Price, K. H., Gavin, J. H., \& Florey, A. T. 2002. Time, teams, and task performance: Changing effects of surface- and deep-level diversity on group functioning. Academy of Management Journal, 45: 1029-1045.

Hebl, M. R., \& Dovidio, J. F. 2005. Placing the "social" back in the examination of social stigma. Personality and Social Psychology Review, 9: 156-182.

Herring, C. 2009. Does diversity pay? Race, gender, and the business case for diversity. American Sociological Review, 74: 208-224. 
James, L. R., Demaree, R. G., \& Wolf, G. 1993. $r_{W G}$ : An assessment of within-group interrater agreement.. Journal of Applied Psychology, 78: 306-309.

James, L. R., Mulaik, S. A., \& Brett, J. M. 2006. A tale of two methods. Organizational Research Methods, 9: 233-244.

Jehn, K., Chadwick, C., \& Thatcher, S. 1997. To agree or not to agree: The effects of value congruence, individual demographic dissimilarity, and conflict on workgroup outcomes. International Journal of Conflict Management, 8: 287-305.

Jehn, K., Northcraft, G. \& Neale, M., 1999. Why differences make a difference: A field study of diversity, conflict, and performance in workgroups. Administrative Science Quarterly, 44: 741-763.

Johns, G. 2006. The essential impact of context on organizational behavior. Academy of Management Review, 31: 386-408.

Johnson, J. W. 2000. A heuristic method for estimating the relative weight of predictor variables in multiple regression. Multivariate Behavioral Research, 35: 1-19

Johnson, P. R., \& Indvik, J. 2001. Rudeness at work: Impulse over restraint. Public Personnel Management, 30: 457-466.

Joshi, A., \& Roh, H. 2009. The role of context in work team diversity research: A meta-analytic review. Academy of Management Journal, 52: 599-627.

Kern, J. H., \& Grandey, A. A. 2009. Customer incivility as a social stressor: The role of race and racial identity for service employees. Journal of Occupational Health Psychology, 14: $46-57$.

Kanter, R. M. 1977. Men and women of the corporation. New York: Basic Books. 
King, E. B., Hebl, M. R., George, J. M., \& Matusik, S. F. 2010. Understanding tokenism: Negative consequences of perceived gender discrimination in male-dominated organizations. Journal of Management.

Klein, K. J., Ziegert, J. C., Knight, A. P., Xiao, Y. 2006. Dynamic delegation: Shared, hierarchical, and deindividualized leadership in extreme action teams. Administrative Science Quarterly, 50: 590-621.

Lam, B. C. C., Lee, J., \& Lau, Y. L. 2004. Hand hygiene practices in a neonatal intensive care unit: A multimodal intervention and impact on nosocomial infection. Pediatrics, 114: $565-571$.

Laveist, T. A., Nuru-Jeter, A., \& Jones, K. E. 2003. The association of doctor-patient race concordance with health services utilization. Journal of Public Health Policy, 24: 312323.

Laveist, T. A., \& Nuru-Jeter, A. 2002. Is doctor-patient race concordance associated with greater satisfaction with care? Journal of Health And Social Behavior, 43: 296-306.

Leary, M. R., \& Downs, D. L. 1995. Interpersonal functions of the self-esteem motive: The selfesteem system as a sociometer. In M. H. Kernis (Ed.), Efficacy, agency, and self-esteem (pp. 123-144). New York: Plenum Press.

Leonard, J. S., D. I. Levine, A. Joshi. 2004. Do birds of a feather shop together? The effects on performance of employees' similarity with one another and with customers. Journal of Organizational Behavior, 25; 731-754.

Liao, H., \& Chuang, A. 2004. A multilevel investigation of factors influencing employee service performance and customer outcomes. Academy of Management Journal, 47: 41-58. 
Lim, S., Cortina, L. M., \& Magley, V. J. (2008). Personal and workgroup incivility: Impact on work and health outcomes. Journal of Applied Psychology, 93: 95-107.

Massey, F. J. 1951. The Kolmogorov-Smirnov test for goodness of fit. Journal of the American Statistical Association, 46: 68-78.

Mayer, D. M., Ehrhart, M. G., \& Schneider, B. 2009. Service attribute boundary conditions of the service climate-customer satisfaction link. Academy of Management Journal, 52: $1034-1050$

McGuire, J. 1984. Search for the self: Going beyond self-esteem and the reactive self. In R. A. Zucker, J. Aronoff, \& A. I. Rabin (Eds.), Personality and the prediction of behavior: 73 120. New York: Academic Press.

McKay, P. F., \& Avery, D. R. 2006. What has race got to do with it? Unraveling the role of racioethnicity in job seekers' reactions to site visits. Personnel Psychology, 59: 395-429.

Mittman, B. S. 1992. Theoretical and methodological issues in the study of organizational demography and demographic change. In P. S. Tolbert \& S. B. Bacharach (Eds.), Research in the Sociology of Organizations (Vol. 10, pp. 3-53). Greenwich, CT: JAI Press.

Morrison, A. 1992. The new leaders: Guidelines on leadership diversity in America. San Francisco: Jossey-Bass.

Muthén, L.K. and Muthén, B.O. 2006. Mplus. Los Angeles: Muthén and Muthén.

Office of the Deputy Prime Minister 2004. The English Indices of Deprivation 2004: Summary (revised). Available online: http://www.communities.gov.uk/documents/communities/pdf/131206.pdf

Oliver, R. 1997. Satisfaction: A behavioral perspective on the consumer. Boston: McGraw-Hill. 
Perloff, R. M., Bonder, B., Ray, G. B., Ray, E. B., \& Siminoff, L. A. 2006. Doctor-patient communication, cultural competence, and minority health: The theoretical and empricial perspectives. American Behavioral Scientist, 49: 835-852.

Preacher, K. J., \& Hayes, A. F. 2004. SPSS and SAS procedures for estimating indirect effects in simple mediation models. Behavioral Research Methods, Instruments and Computers, 36: 717-731.

Pugh, S. D., Dietz, J., Brief, A. P., \& Wiley, J. W. 2008. Looking inside and out: The impact of employee and community demographic composition on organizational diversity climate. Journal of Applied Psychology, 93: 1422-1428.

Reichheld, F. F., \& Sasser, W. E. 1990. Zero defections: Quality comes to services. Harvard Business Review, 68: 105-111.

Reskin, B., McBrier, D., \& Kmec, J. 1999. The determinants and consequences of workplace sex and race composition. Annual Review of Sociology, 25: 335-361.

Richard, O. 2000. Racial diversity, business strategy, and firm performance: A resource-based view. Academy of Management Journal, 43: 164-177.

Richard, O., Barnett, T., Dwyer, S., \& Chadwick, K. 2004. Cultural diversity in management, firm performance, and the moderating role of entrepreneurial orientation dimensions. Academy of Management Journal, 47: 255-266.

Richard, O., Murthi, B. P. S., \& Ismail, K. 2007. The impact of racial diversity on intermediate and long-term performance: The moderating role of environmental context. Strategic Management Journal, 28: 1213-1233.

Richeson, J. A., \& Shelton, J. N. 2003. When prejudice does not pay: Effect of interracial contact on executive function. Psychological Science, 14: 287-290. 
Roberson, Q., \& Stevens, C. K. 2006. Making sense of diversity in the workplace:

Organizational justice and language abstraction in employees' accounts of diversityrelated incidents. Journal of Applied Psychology, 91: 379-391.

Roberts, L. M. 2005. Changing faces: Professional image construction in diverse organizational settings. Academy of Management Review, 90: 695-711.

Rogg, K. L., Schmidt, D. B., Shull, C., \& Schmitt, N. 2001. Human resource practices, organizational climate, and customer satisfaction. Journal of Management, 2: 431-449.

Rust, R. T., Zahorik, A. J., \& Keiningham, T. L. 1995. Return on quality ROQ: Making service quality financially accountable. Journal of Marketing, 59: 58-70.

Sacco, J. M., \& Schmitt, N. 2005. A dynamic multilevel model of demographic diversity and misfit effects. Journal of Applied Psychology, 90: 203-231.

Schimel, J., Simon, L., Greenberg, J., Pyszczynski, T., Solomon, S., Waxmonsky, J., \& Arndt, J. 1999. Stereotypes and terror management: Evidence that mortality salience enhances stereotypic thinking and preferences. Journal of Personality and Social Psychology, 77: 905-926.

Sen, S., \& Bhattacharya, C. B. 2001. Does doing good always lead to doing better? Consumer reactions to corporate social responsibility. Journal of Marketing Research, 38: 225243.

Shipton, H., West, M. A., Parkes, C. L., Dawson, J. F., \& Patterson, M. G. (2006). When promoting positive feelings pays: Aggregate job satisfaction, work design features, and innovation in manufacturing organizations. European Journal of Work \& Organizational Psychology: 1-27. 
Why Organizational and Community 38

Shrout, P. E., \& Bolger, N. 2002. Mediation in experimental and nonexperimental studies: New procedures and recommendations. Psychological Methods, 7: 422-445.

Simons. T., Pelled, L.H., \& Smith, K.A. 1999. Making use of difference: Diversity, debate, and decision comprehensiveness in top management teams. Academy of Management Journal, 42: 662-673.

Sitzia, J., \& Wood, N. 1997. Patient satisfaction: A review of issues and concepts. Social Science \& Medicine, 45: 1829-1843.

Skaggs, B.C., \& Huffman, T. R. 2003. A customer interaction approach to strategy and production complexity alignment in service firms. Academy of Management Journal, 46: 775-786.

Schneider, B., Ehrhart, M. G., Mayer, D. M., Saltz, J. L., \& Niles-Jolly K. 2005. Understanding organizational-customer linkages in service settings. Academy of Management Journal, 48: 1017-1032.

Schneider, B. 2004. Welcome to the world of services management. Academy of Management Executive, 18: 144-150.

Sherbourne, C. D., Hays, R. D., Ordway, L., DiMatteo, M. R., \& Kravitz, R. L. 1992. Antecedents of adherence to medical recommendations: Results from the medical outcomes study. Journal of Behavioral Medicine, 15: 447-468.

Spreng, R. A., MacKenzie, S. B., \& Olshavsky, R. W. 1996. A re-examination of the determinants of consumer satisfaction. Journal of Marketing, 60: 15-32.

Staples, D.S. \& Zhao, L. 2005. The effects of cultural diversity in virtual teams versus face-toface teams. Group Decision and Negotiation, 15: 389-406. 
Staw, B. M., Sutton, R. I., \& Pelled, L. H. 1994. Employee positive emotion and favorable outcomes at the workplace. Organization Science, 5: 51-71.

Stewart, M. A. 1995. Effective physician-patient communication and health outcomes: A review. Canadian Medical Association Journal, 152: 1423-1433.

Stewman, S. 1988. Organizational demography. Annual Review of Sociology, 14, 173-202.

Tajfel, H., Billig, M., Bundy, R. P. \& Flament, C. 1971. Social categorization and intergroup behaviour. European Journal of Social Psychology, 2: 149-178,

Tafjel, H. \& Turner, J. C. 1979. An integrative theory of intergroup conflict. In W. G. Austin, \& S. Worchel (Eds.), The social psychology of intergroup relations (pp. 33-47). Monterey, CA: Brooks/Cole.

Trawalter, S., Richeson, J. A., \& Shelton, J. N. 2009. Predicting behavior during interracial interactions: A stress and coping approach. Personality and Social Psychology Review, 13: $243-268$.

United Nations Statistics Division 2009. Ethnocultural characteristics. Retrieved online October 24, 2009: http://unstats.un.org/unsd/demographic/sconcerns/popchar/default.htm

Weick, K. 1976, Educational organizations as loosely coupled systems. Administrative Science Quarterly, 21: 1-9.

Wigboldus, D. H. J., Sherman, J. W., Franzese, H. L., \& van Knippenberg, A. 2004. Capacity and comprehension: Spontaneous stereotyping under cognitive load. Social Cognition, 22: 292-309. 
TABLE 1

Means, Standard Deviations and Intercorrelations of all Study Variables

\begin{tabular}{|c|c|c|c|c|c|c|c|c|c|c|}
\hline & Mean & SD & 1. & 2. & 3. & 4. & 5. & 6. & 7. & 8. \\
\hline 1. Hospital size & 4167 & 2259 & & & & & & & & \\
\hline 2. Location ${ }^{1}$ & 0.18 & 0.38 & $-0.19 *$ & & & & & & & \\
\hline 3. Socioeconomic status & 21.21 & 8.93 & $0.28 * *$ & $0.19 *$ & & & & & & \\
\hline 4. Organizational diversity & 0.25 & 0.16 & -0.11 & $0.82 * *$ & $0.18^{*}$ & & & & & \\
\hline 5. Community diversity & 0.15 & 0.16 & 0.04 & $0.76 * *$ & $0.42 * *$ & $0.90 * *$ & & & & \\
\hline 6. Demographic representativeness & 0.13 & 0.08 & $0.32 * *$ & $-0.48 * *$ & $0.21 *$ & $-0.64 * *$ & $-0.28 * *$ & & & \\
\hline 7. Civility towards service recipients & 79.22 & 2.53 & $0.18 *$ & $-0.44 * *$ & -0.02 & $-0.56 * *$ & $-0.46^{* *}$ & $0.50 * *$ & & \\
\hline 8. Quality of services & 3.04 & 0.80 & -0.02 & $-0.23 * *$ & -0.04 & $-0.25 * *$ & $-0.23 * *$ & $0.18 *$ & $0.36^{* *}$ & \\
\hline 9. Use of resources & 2.92 & 1.01 & 0.13 & $-0.22 * *$ & $0.21 *$ & $-0.19 *$ & -0.13 & $0.26^{* *}$ & $0.36 * *$ & $0.36 * *$ \\
\hline
\end{tabular}

Notes:

$* \mathrm{p}<.05$

$* * \mathrm{p}<.01$

${ }^{1} 1$ = London, $0=$ Outside London 
TABLE 2

Results of Regression Analyses for Hypotheses 1 to 3

\begin{tabular}{|c|c|c|c|c|c|}
\hline Hypothesis & 1 & 2 & 2 & 3 & 3 \\
\hline Dependent variable & Civility & $\begin{array}{l}\text { Quality of } \\
\text { services }\end{array}$ & $\begin{array}{c}\text { Use of } \\
\text { resources }\end{array}$ & $\begin{array}{l}\text { Quality of } \\
\text { services }\end{array}$ & $\begin{array}{l}\text { Use of } \\
\text { resources }\end{array}$ \\
\hline Hospital size & $0.00(0.00)$ & $0.00(0.00)$ & $-0.00(0.00)$ & $-0.00(0.00)$ & $0.00(0.00)$ \\
\hline Location $^{1}$ & $0.73(0.81)$ & $-0.71(0.70)$ & $-0.89(0.70)$ & $-0.44(0.42)$ & $-0.83(0.49)$ \\
\hline Socioeconomic status & $0.00(0.03)$ & $0.00(0.03)$ & $0.06(0.02)^{* *}$ & $0.00(0.01)$ & $0.04(0.02)^{* *}$ \\
\hline Community diversity & $1.90(3.015)$ & $-0.17(1.79)$ & $0.18(1.79)$ & $-0.56(1.70)$ & $-2.10(1.67)$ \\
\hline Intraorganizational diversity & $-11.41(3.10)^{* *}$ & & & $0.84(1.83)$ & $3.02(1.81)$ \\
\hline Civility & & $0.27(0.08)^{* *}$ & $0.25(0.08)^{* *}$ & $0.16(0.03)^{* *}$ & $0.16(0.04)^{* *}$ \\
\hline $\begin{array}{l}\text { Intraorganizational diversity via } \\
\text { Civility (indirect effect) }\end{array}$ & & & & $-1.89(0.62)^{* *}$ & $-1.96(0.77)^{*}$ \\
\hline Total $\mathrm{R}^{2}$ & .33 & .18 & .20 & .18 & .23 \\
\hline $\mathrm{R}^{2}$ due to focal independent variable & $.06 * *$ & $.09 * *$ & $.07 * *$ & .00 & .02 \\
\hline $\begin{array}{l}\text { Notes: } \\
* \mathrm{p}<.05 \\
* * \mathrm{p}<.01 \\
{ }^{1} 1=\text { London, } 0=\text { Outside London }\end{array}$ & & & & & \\
\hline
\end{tabular}


TABLE 3

Results of Regression Analyses for Hypotheses 4 and 5

\begin{tabular}{|c|c|c|c|c|}
\hline Hypothesis & $4 \mathrm{a}$ & $4 \mathrm{~b}$ & 5 & 5 \\
\hline Dependent variable & Civility & Civility & Quality of services & Use of resources \\
\hline Hospital size & $0.00(0.00)$ & $0.00(0.00)$ & $-0.00(0.00)$ & $-0.00(0.00)$ \\
\hline Location $^{1}$ & $-1.45(0.56)^{*}$ & $0.62(0.80)$ & $-0.45(0.43)$ & $-0.92(0.54)$ \\
\hline Socioeconomic status & $-0.02(0.02)$ & $0.01(0.03)$ & $0.01(0.02)$ & $0.05(0.02)^{* *}$ \\
\hline Community diversity & & $-8.45(5.51)$ & $-1.86(3.02)$ & $-8.85(2.78)^{* *}$ \\
\hline Intraorganizational diversity & & $2.02(6.73)$ & $2.49(3.76)$ & $11.67(3.86)^{* *}$ \\
\hline Demographic representativeness & $12.05(2.85)^{* *}$ & $13.46(6.01)^{*}$ & $1.74(3.23)$ & $8.76(3.51)^{*}$ \\
\hline Civility & & & $0.15(0.04)^{* *}$ & $0.15(0.05)^{* *}$ \\
\hline Intraorganizational diversity via & & & $0.46(1.13)$ & $0.46(1.08)$ \\
\hline Civility (indirect effect) & & & & \\
\hline $\begin{array}{l}\text { Demographic representativeness via } \\
\text { Civility (indirect effect) }\end{array}$ & & & $2.33(1.07)^{*}$ & $2.24(1.09)^{*}$ \\
\hline Total $\mathrm{R}^{2}$ & .29 & .36 & .19 & .27 \\
\hline $\mathrm{R}^{2}$ due to focal independent variable & $.09 * *$ & $.02 *$ & .00 & .04 \\
\hline $\begin{array}{l}\text { Notes: } \\
*^{*} p<.05 \\
* * p<.01 \\
1=\text { London, } 0=\text { Outside London }\end{array}$ & & & & \\
\hline
\end{tabular}




\section{Appendix}

1. When you had important questions to ask a doctor, did you get answers that you could understand?

2. Did you have confidence and trust in the doctors treating you?

3. Did doctors talk in front of you as if you weren't there?

4. When you had important questions to ask a nurse, did you get answers that you could understand?

5. Did you have confidence and trust in the nurses treating you?

6. Did nurses talk in front of you as if you weren't there?

7. Sometimes in a hospital, a member of staff will say one thing and another will say

- something quite different. Did this happen to you?

8. Were you involved as much as you wanted to be in decisions about your care and treatment?

9. How much information about your condition or treatment was given to you?

10. If your family or someone else close to you wanted to talk to a doctor, did they have enough opportunity to do so?

11. Did you find someone on the hospital staff to talk to about your worries and fears?

12. Were you given enough privacy when discussing your condition or treatment?

13. Were you given enough privacy when being examined or treated?

14. Overall, did you feel you were treated with respect and dignity while you were in the hospital? 


\section{Biographical Sketches}

Eden B. King (eking6@gmu.edu) is an assistant professor of psychology at George Mason University. She received her Ph.D. in organizational psychology from Rice University. Her research focuses on understanding and improving the experiences of stigmatized employees.

Jeremy Dawson (j.f.dawson@aston.ac.uk) is a senior research fellow at Aston Business School, Aston University. His research focuses on the management of healthcare professionals, diversity and team working processes, and the application of statistical procedures to research in management and psychology.

Michael A. West (m.a.west@aston.ac.uk) is Professor of Organizational Psychology at Lancaster University Management School, UK. He received his $\mathrm{PhD}$ from the University of Wales. His research focuses on team innovation and effectiveness and on the links between leadership, HRM and health services effectiveness.

Veronica L. Gilrane (vgilrane@gmu.edu) is a doctoral student in the industrial organizational department of psychology at George Mason University. Her primary research interests are in workplace diversity and inclusion with a particular focus on perceptions and experiences of women and minorities.

Chad I. Peddie (cpeddie1@gmu.edu) is a doctoral student in the Industrial Organizational Psychology Program at George Mason University. His general research interests involve organizational diversity and the experiences of minority group members in the workplace.

Lucy Bastin (1.bastin@aston.ac.uk) is a Senior Lecturer in Computer Science at Aston University, UK. Her research applies spatio-temporal analysis techniques to a variety of environmental, ecological and socio-demographic challenges, including disease mapping and monitoring, conservation planning and emergency decision making. 